\title{
Optimization of Thermal and Mechanical Properties of Unsaturated Polyester Resin as a Binder in Polymer Concrete for Manufacturing Precision Tool Machine Bases
}

Haddad $\mathrm{H}^{*}$ and Sbarski I

Swinburne University of Technology, Australia

\begin{abstract}
This study investigates the effect of unsaturated polyester resin chemical composition on the coefficient of thermal expansion, damping properties, flexural strength, tensile strength and hardness. The resin is used as binder in polymer concrete for manufacturing the bases of precision tool machines in previous work published by the authors. Resins of various ratios of styrene-ARAPOL and methyl methacrylate (MMA)-ARAPOL were made and their curing kinetics was studied using viscosity measurements and exothermic reaction temperature profiles. The resins were studied using dynamic mechanical analysis and in-house thermal expansion measuring devices. It was found that ARAPOL-MMA (60:40) has the highest damping factor of $5.46 \%$, and the thermal expansion coefficient of $7.98 \times 10$ $5 /{ }^{\circ} \mathrm{C}$. This composition also has the optimum flexural and tensile strengths at $128 \mathrm{MPa}$ and $58.6 \mathrm{MPa}$.
\end{abstract}

Keywords: Polymer concrete; Resin binder; Thermosetting polymer; Precision tool machine bases; Coefficient of thermal expansion; Damping factor

\section{Introduction}

Unsaturated polyester resins (UPEs) are thermosetting materials used as the binding matrix in polymer concretes (PCs) and other composite materials [1,2]. UPEs cure via the radical copolymerization of a monomer and the low molecular weight unsaturated polyester liquid when an initiator and an accelerator are added at ambient conditions [3-6]. UPE curing is an exothermic reaction accompanied with viscosity growth due to molecular weight increase to form a threedimensional cross-linked network [7-11]. The mechanical properties of the resin and its adhesion to aggregates in PC are the main sources of the advantageous mechanical properties of PC for its application in precision tool machine bases [12,13], where PCs (polymer concretes) are used due to their high damping properties and their ability to absorb unwanted system vibrations [14].

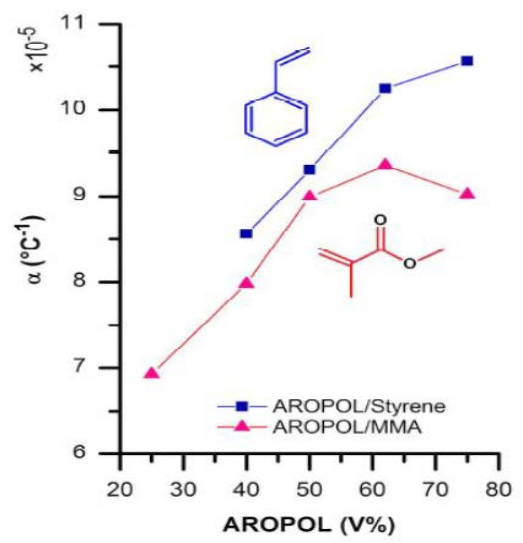

Several strategies to improve UPE properties have been reported. When a rubbery phase is introduced into a polymeric matrix, the mobility of the rubber molecules enhances the dissipation of vibration energy in the resin [15-17]. Synthetic and natural rubbers and elastomers in solid and liquid forms have been applied to improve UPE damping properties. Rubbers such as natural rubber latex (NRL) $[16,18]$ and styrene-butadiene rubber (SBR) latex $[19,20]$, and functional elastomers such as hydroxyl-terminated polybutadiene, deoxidized natural rubber, hydroxyl terminated natural rubber, and maleated nitrile rubber [15] have been used to enhance UPE damping properties. Also Polyoxypropylenetriamine (POPTA) has also been employed, combined with temperature during curing, to optimize the damping factor and mechanical properties of UPE [21]. In addition polyhedral oligomeric silsesquioxanes (EA-POSS) has been used to improve the damping behaviour and other mechanical properties of UPE $[4,22]$. These modifications increase the toughness and tensile strength of UPE resin. The dissimilarity of the rubbery and resin phases results in miscibility problems which researchers have attempted to solve using copolymerizing terminal groups [23] and dispersants and solvents [16].

Copolymers of UPE and polyurethanes [24,25], polyureas, polysiloxanes, polyimides or polyglycols also produce resins with improved damping properties [26]. Butadiene as a vinyl monomer has also been employed to modify UPE resin's mechanical properties [27].

Curing and processing conditions also have significant effects on UPE's mechanical properties [28]. Research literature suggests that varying the resin curing rate via curing temperature [29] or initiation mechanism or post-curing heat treatment of the resin affect UPE resin damping properties. Li et al. [30] studied the effect of high temperature curing and post-curing heat treatment on the microheterogeneity of UPE and its effect on its mechanical properties. Kim et al. [31] used UV initiation curing of UPE and found that the type and the amount of photo initiator affect the level of improvement in mechanical properties.

*Corresponding author: Header Haddad, Swinburne University of Technology, Australia, Tel: +61 39214 8000; E-mail: headerhaddad@swin.edu.au

Received November 06, 2017; Accepted November 14, 2017; Published November 24, 2017

Citation: Haddad H, Sbarski I (2017) Optimization of Thermal and Mechanical Properties of Unsaturated Polyester Resin as a Binder in Polymer Concrete for Manufacturing Precision Tool Machine Bases. J Material Sci Eng 6: 395. doi: 10.4172/2169-0022.1000395

Copyright: ( $2017 \mathrm{Haddad} \mathrm{H}$, et al. This is an open-access article distributed under the terms of the Creative Commons Attribution License, which permits unrestricted use, distribution, and reproduction in any medium, provided the original author and source are credited. 
Citation: Haddad H, Sbarski I (2017) Optimization of Thermal and Mechanical Properties of Unsaturated Polyester Resin as a Binder in Polymer Concrete for Manufacturing Precision Tool Machine Bases. J Material Sci Eng 6: 395. doi: 10.4172/2169-0022.1000395

Sanchez et al. [32] showed that the styrene ratio in UPE prepolymerization mixture affects the phase continuity of resin after curing due to the limited miscibility of polystyrene in UPE. This phase separation can be affected dramatically by curing temperature [33]

The operational drawbacks of PC when used as bases of precision machines include its coefficient of thermal expansion (CTE), high shrinkage [34,35] and low creep resistance [36]. According to Valore [37], the CTE is high in PCs containing UPE resin in comparison to cast iron and other metal inserts. Precision machines have a complex combination of metal inserts and connecting plastic pipes for fluids in the PC base [31]. This leads to a non-uniform distribution of thermal expansion for the base during operation. It has been reported that reduction of the resin-to-aggregate volumetric ratio in the $\mathrm{PC}$ reduces its CTE [31]. Achieving a CTE for the PC as close as possible to that of the precision machine metal components can enhance the distribution of thermal expansion of the base.

The main purpose of this study is to optimize the resin binder through its chemical composition to achieve the lowest CTE and highest damping properties combined with good mechanical properties. The study also considers the manufacturing conditions of PC, including the low initial viscosity of UPE resin to obtain good wetting of aggregate particles during the initial mixing process. A low curing temperature of UPE resin is required for this application to reduce the thermal stresses. The resin is used as binder in polymer concrete for manufacturing the bases of precision tool machines in previous work published by the authors [12].

\section{Experimental Section}

\section{Materials}

The UPE resin was made from a commercial unsaturated polyester AROPOL (67\% unsaturated polyester dissolved in 33\% styrene) obtained from Huntsman Chemical Company (Australia), methyl methacrylate (MMA) from Degussa (Australia), cobalt octoate and dimethyl aniline (DMA) from Alfa Aesar (USA), and methyl ethyl kenton peroxide (MEKP) NR20 from Nuplex Industries (Australia).

\section{Specimen preparation}

A typical resin sample was produced by mixing a volumetric $3: 2$ ratio of UP to MMA by hand. To this mixture, $0.8 \%$ cobalt octoate (promoter), 0.2\% DMA (accelerator) and 2\% (v/v) MEKP (initiator) were added and mixed respectively. The mixture was cast in a high density polyethylene (HDPE) mould dimensions were $55 \mathrm{~mm} \times 15 \mathrm{~mm}$ $\times 10$ and cured in ambient conditions for 24 hours.

\section{Kinetics}

A Brookfield RVDV-II+Pro viscometer (USA) was used to determine the copolymerization mixture's viscosity during the reaction. Gel time was determined for the resin according ASTM D 2471-99. The reaction mixture temperature profile was measured using a thermocouple (SE00 type K thermocouple, Pico Technology, UK).

\section{Mechanical measurements}

The three-point bending flexural test was carried out on resin samples using a Zwick Z010 (Germany) machine to evaluate tensile and flexural strength. The specimen dimensions were $50 \mathrm{~mm} \times 10$ $\mathrm{mm} \times 2.5 \mathrm{~mm}$. A Zwick 3130/3131 (Germany) machine was used to measure the Shore D hardness of the resin samples. Dynamic oscillatory measurements were conducted using Dynamic Mechanical Analysis (DMA) (TA Instruments, SDT 2960, USA) to evaluate the specimens' damping ratio $(\tan \delta)$ using a dual cantilever measuring system.

\section{Thermal expansion measurements}

The coefficient of thermal expansion (CTE) was measured using a custom-built device. Samples were cylindrical, $10 \mathrm{~mm}$ in diameter and $70 \mathrm{~mm}$ in length. The device includes a heating chamber (Thumler Model number TH2700-26, Germany) with two displacement probes attached to a digital display unit (SYLVAC DSOS, Switzerland) and a thermostat connected to temperature control microprocessor. The UPE resin sample temperature was obtained using a data acquisition system connected to a computer, as illustrated in Figure 1.

Two rods made of Invar were used in this set-up. Invar is a $36 \%$ nickel-iron alloy with the lowest CTE among metal alloys in the 20$230^{\circ} \mathrm{C}$ range, $\alpha i=1.2 \times 10^{-6} /{ }^{\circ} \mathrm{C}$. One of the rods was used as a reference and the other was placed above the PC sample. The expansion of the reference rod and the sample with the second rod is monitored by the probes on the top of the heating chamber. Figure 1 shows this arrangement. The UPE resin sample had a hole in the centre in order to place the thermocouple sensor (SE00 type K thermocouple, Pico Technology, UK) to monitor and control the temperature inside the

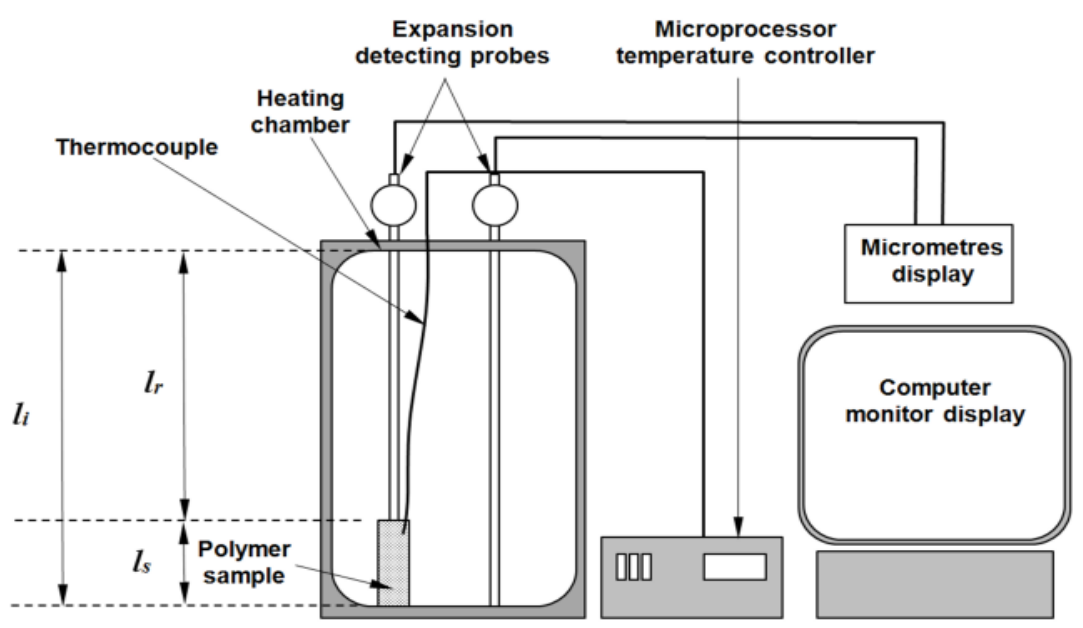

Figure 1: Thermal expansion measurement in house setup. 
Citation: Haddad H, Sbarski I (2017) Optimization of Thermal and Mechanical Properties of Unsaturated Polyester Resin as a Binder in Polymer Concrete for Manufacturing Precision Tool Machine Bases. J Material Sci Eng 6: 395. doi: 10.4172/2169-0022.1000395

Page 3 of 7

sample. The Pico data acquisition system contains TC-08 thermocouple data logger (Pico technology, UK). Due to the low thermal conductivity of UPE resin, approximately half hour is required to ensure the thermal equilibrium of the sample. Thermal expansion was measured at 25,35 , 40,50 and $60^{\circ} \mathrm{C}$. The CTE of each resin sample was calculated using the following equation:

$$
\alpha_{s}=\frac{\Delta S}{l_{s} \Delta T}+\alpha_{i},
$$

derived according to the physical principle of thermal expansion as follows;

$$
\begin{aligned}
& \Delta L=\alpha_{i r} l_{r} \Delta T+\alpha_{s s} l_{s} \Delta T \\
& \Delta R=\alpha_{i} l_{r} \Delta T+\alpha_{i} l_{s} \Delta T
\end{aligned}
$$$$
\Delta S=\Delta L-\Delta R
$$

$l_{r}$ is the length of the Invar rod, which is located on top of the resin sample, $l$ is the length of the resin sample, and $\Delta L$ is the change of the length for the Invar rod and the sample and $\Delta R$ is the change in length of the reference Invar rod within the temperature difference $\Delta T . \Delta S$ are the difference between the readings of the two probes, i.e. the difference between $\Delta L$ and $\Delta R$.

\section{Results and Discussion}

\section{Resin curing kinetics}

PCs containing polymethyl methacrylate as a binder show a high modulus of elasticity [38] and very low CTE [39] making MMA a good candidate to control and balance both the mechanical and CTE characteristics of the binding polymer in PC. The PC damping properties can be modified using the styrene component of the resin due to the low miscibility of polystyrene in UP and phase separation [32]. In this research program, several compositions of UP: styrene: MMA were prepared to study various aspects of the curing process and mechanical properties of the binding resin.

Resins with ARAPOL: styrene or MMA ratios varying between 25:75 and 68:32 were prepared. The curing rate in the formulations studied shows a decrease with increasing MMA or styrene ratios. The curing rates for compositions with MMA decrease further in comparison with compositions containing styrene. This is an indication that the reactivity ratio of styrene is higher than that of MMA in the UP radical copolymerising system. Figure $2 \mathrm{~A}$ and $2 \mathrm{~B}$ show the rate of viscosity increase of ARAPOL: styrene and MMA during the curing process.

Increasing the MMA and styrene ratios decreases the initial
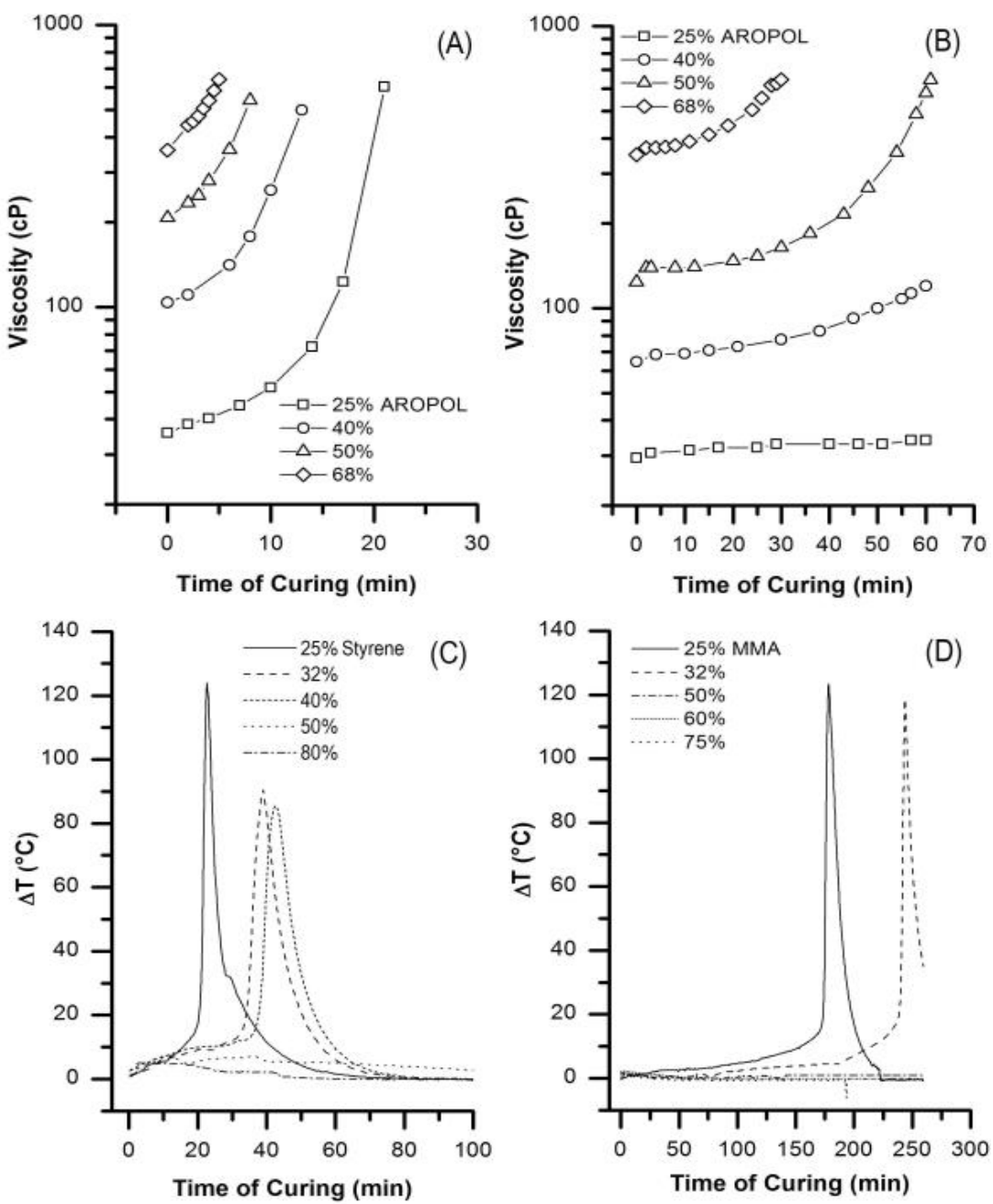

Figure 2: Viscosity increase of (A) ARAPOL: styrene and (B) ARAPOL: MMA, and temperature profile of (C) ARAPOL: styrene and (D) ARAPOL: MMA resines during reaction mixture curing. 
Citation: Haddad H, Sbarski I (2017) Optimization of Thermal and Mechanical Properties of Unsaturated Polyester Resin as a Binder in Polymer Concrete for Manufacturing Precision Tool Machine Bases. J Material Sci Eng 6: 395. doi: 10.4172/2169-0022.1000395

Page 4 of 7

viscosity of the polymerising mixture. The initial viscosity of the polymerising mixture is also important in the processing of PC. Lower initial viscosity enhances the mixing efficiency with the initiator and promoter and allows for more efficient diffusion of the binding resin in the space between the aggregate particles in the concrete.

Figure $2 \mathrm{C}$ and $2 \mathrm{D}$ show the temperature profile of the curing exothermic process for the above- mentioned compositions. Peak temperature reduces from $124^{\circ} \mathrm{C}$ at $22 \mathrm{~min}$ in $25 \%$ styrene to $84^{\circ} \mathrm{C}$ at $41 \mathrm{~min}$ in $40 \%$ styrene in ARAPOL. Higher ratios of styrene do not produce a temperature peak. Similar behaviour was observed in ARAPOL:MMA compositions. Peak temperature reduces from $122^{\circ} \mathrm{C}$ at $178 \mathrm{~min}$ in $25 \% \mathrm{MMA}$ to $117^{\circ} \mathrm{C}$ at $243 \mathrm{~min}$ in $32 \% \mathrm{MMA}$ in ARAPOL.

The decrease in the curing rate and lowering the peak temperature of the mixture during the curing process is essential to produce a homogeneous resin with no residual thermal stresses that may form a fatigue point in the structure. A slow curing rate and longer fluid initial stages allow for better wetting, more efficient diffusion in pores and spaces between aggregates and time to remove bubbles in the PC mix [40]. The gel time of the above-mentioned resin compositions of UP, styrene and MMA was measured using the ASTM D 2471-99 method. In this method a wooden stick dipped in the resin sample and the resin collected by the stick indicate the gel point. When the adhered resin to the wooden stick is starting to obtain a certain thinness this may record as a gel time. The results of gel time are shown in Figure 3. The gel time increases from 1 to $28 \mathrm{~min}$ in ARAPOL: styrene with increasing styrene ratio. In comparison, in this system, MMA as a monomer with a lower reactivity ratio reduces the curing rate of the resin, increasing the gel time from 6 to $210 \mathrm{~min} 41$. This may be the reason for the ARAPOL: MMA composition possessing better mechanical properties in comparison to ARAPOL: styrene 27.

\section{Flexural strength}

As the resin is the backbone of PC composites, the risen binder forms a high percentage of the flexural strength of PC. Figure 4D illustrates the effect of styrene and MMA volume fraction on maximum flexural strength. ARAPOL/MMA compositions seem to have a higher strength than the ARAPOL/styrene compositions. The addition of

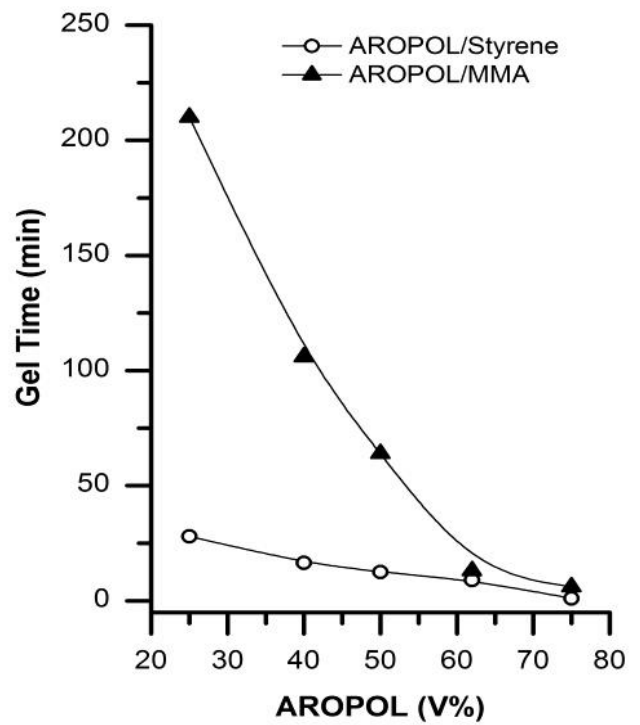

Figure 3: The gel time of styrene and MMA-ARAPOL resins using ASTM D 2471-99 method.
MMA increases the flexural strength of ARAPOL:MMA from 73.7$128 \mathrm{MPa}$ when it reaches the maximum at 40\% ARAPOL: MMA then it deceases, even though the strength is still higher than that of the ARAPOL: styrene compositions. The reactivity coefficient for MMA is lower compared to styrene which is used initially to reduce the initial reaction mixture viscosity and reduce the curing rate of the resin $[41,42]$ this situation enhance mixing initiator and promoter with the composition, this can be the reason for ARAPOL/MMA composition to have good mechanical properties compared to ARAPOL/Styrene composition [27].

\section{Tensile strength}

Tensile strength was tested for different resin compositions. Tensile strength is higher for ARAPOL/MMA than the ARAPOL/styrene compositions at the maximum. The tensile strength of ARAPOL/MMA follows similar behaviour to flexural strength. The highest strength is reached at $40 \%$ ARAPOL/MMA 58.6 MPa, as shown in Figure 4B. The strain is higher for ARAPOL/MMA compositions than for ARAPOL/ styrene, as shown in Figure 4A. The maximum strain is reached at the same resin composition where maximum strength is reached. The modulus of elasticity was calculated. ARAPOL/MMA compositions demonstrate a higher level of modulus of elasticity than the ARAPOL: styrene compositions. Increasing ARAPOL or decreasing MMA increase the modulus of elasticity at various levels of ARAPOL/MMA composition. An increase in the ARAPOL increases the modulus of elasticity of the ARAPOL: styrene compositions, except for the last point in the $75 \%$ ARAPOL/styrene composition, which descends rapidly as it is the lowest, as shown in Figure 4C.

\section{Hardness}

Hardness was measured for a variety of resin compositions. Figure 5 illustrates the relationship between ARAPOL volume fraction and Shore D hardness. It is reasonable to say that an increase in the ARAPOL volume fraction decreases the hardness in the ARAPOL/ MMA composition except with 60\% ARAPOL/MMA as shown in Figure 5A. An increase in the ARAPOL volume fraction does not indicate a trend in the Shore D hardness for the ARAPOL/styrene compositions, as shown in Figure 5B.

\section{Damping factor}

A high damping factor is the primary reason why thermoset resin is used as a binder in PC for the bases of precise tool machinery [43]. This property constructs the functionality to damp vibration generated from servo motors in the precision tool machinery [44]. The damping factor was measured for all compositions of ARAPOL/styrene and ARAPOL/MMA using DMA, except for the 25\% ARAPOL/styrene resin composition, because of the unsuitability of the resin for making a sample. An isothermal frequency sweep for dual cantilever was conducted in the range of frequency of $1-200 \mathrm{~Hz}$, in considering the precise tool precision machine work in the range of 60-6000 RPM [45] and the base structural design, which is a simple supported beam similar to the DAM structural experimental design. Figure $6 \mathrm{~A}$ and $6 \mathrm{~B}$ illustrate the DMA analysis of the results for the damping factor versus frequency for all compositions.

The composition with the highest damping factor (Tan Delta), which is almost constant with frequency sweep, is 40\% ARAPOL/ MMA, reaching a damping factor of 0.0546 . Each composition has its Owen behaviour, and most are a function of frequency. The most constant damping factor and the highest is produced by the $40 \%$ ARAPOL/MMA composition. 

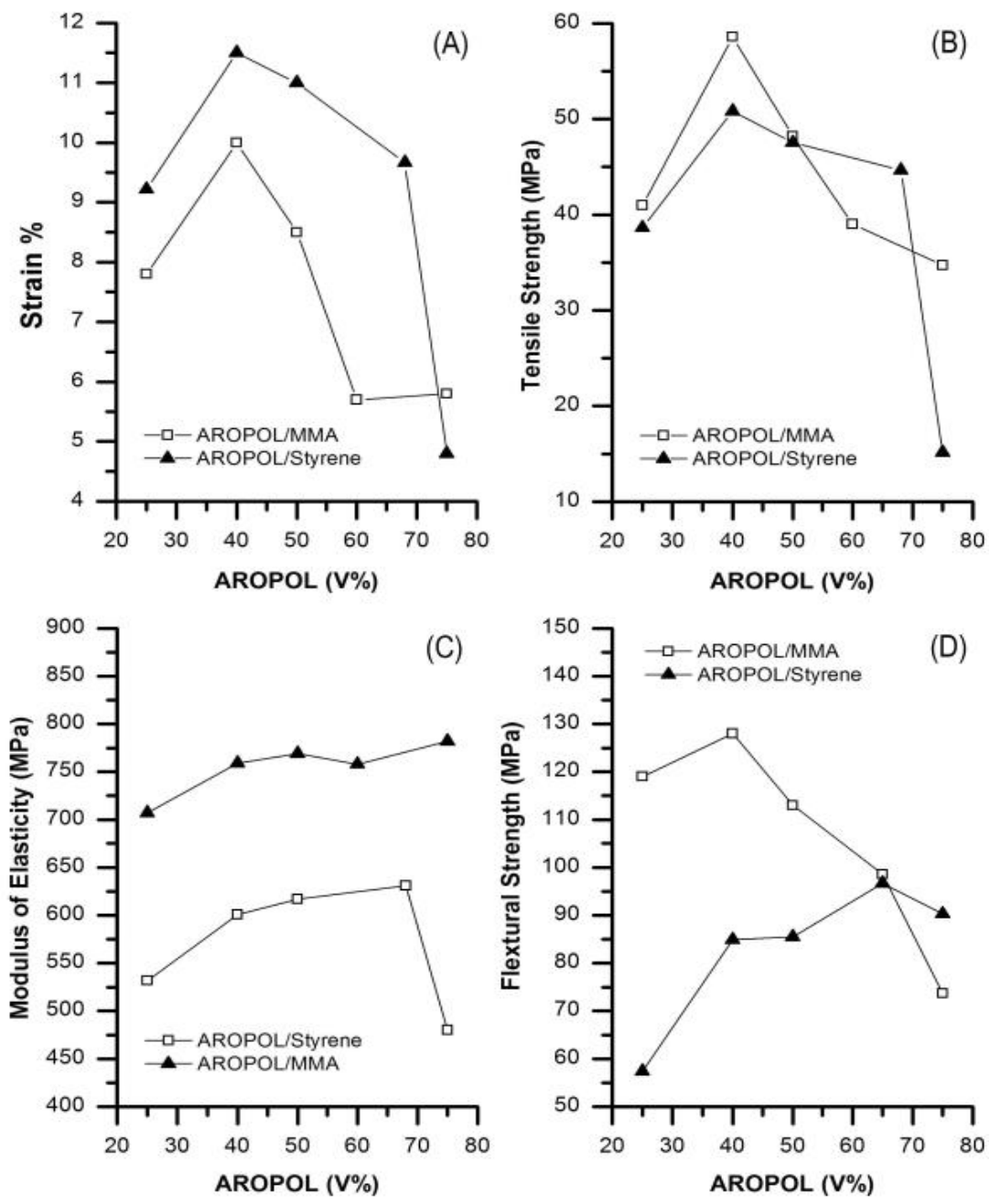

Figure 4: The effect of volume fraction of ARAPOL on (A) strain, (B) tensile strength, (C) modulus of elasticity, and (D) flextural strength of ARAPOL: MMA and ARAPOL: Styrene resins.
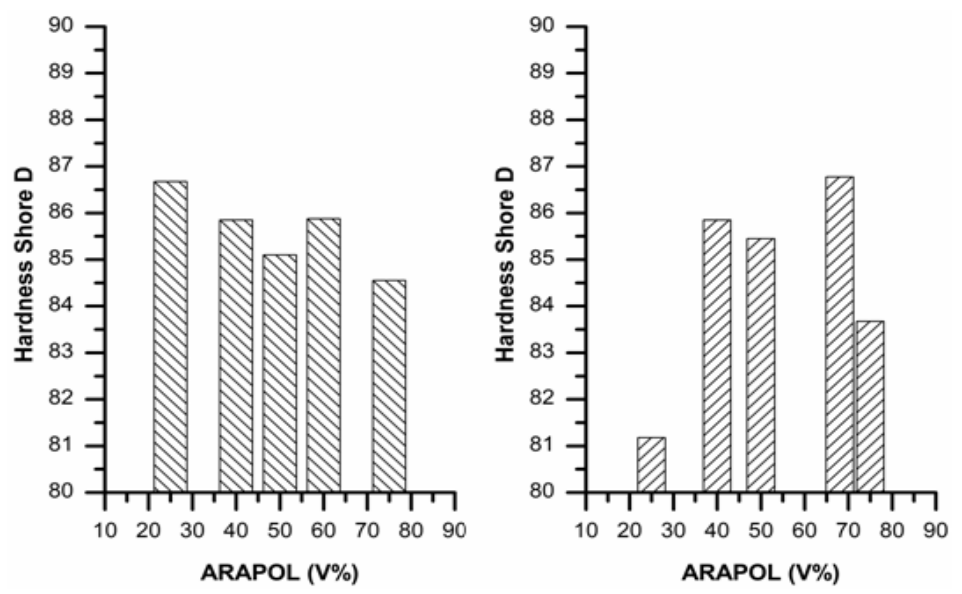

Figure 5: Shor D hardness of $(A) M A A$ and $(B)$ styrene - ARAPOL resines.

\section{Coefficient of thermal expansion (CTE)}

The first order approximation of CTE in PC, as a composite, can be obtained using the mixing rule [46].

$$
\alpha_{\mathrm{c}}=\alpha_{\mathrm{a}} \phi+\alpha_{m}(1-\phi)
$$

Where $\alpha_{c}, \alpha_{m}$ and $\alpha_{a}$ are the CTEs of the composite, matrix resin and filler aggregate, and $\phi$ is the volume fraction of the aggregate. 
Citation: Haddad H, Sbarski I (2017) Optimization of Thermal and Mechanical Properties of Unsaturated Polyester Resin as a Binder in Polymer Concrete for Manufacturing Precision Tool Machine Bases. J Material Sci Eng 6: 395. doi: 10.4172/2169-0022.1000395

Page 6 of 7
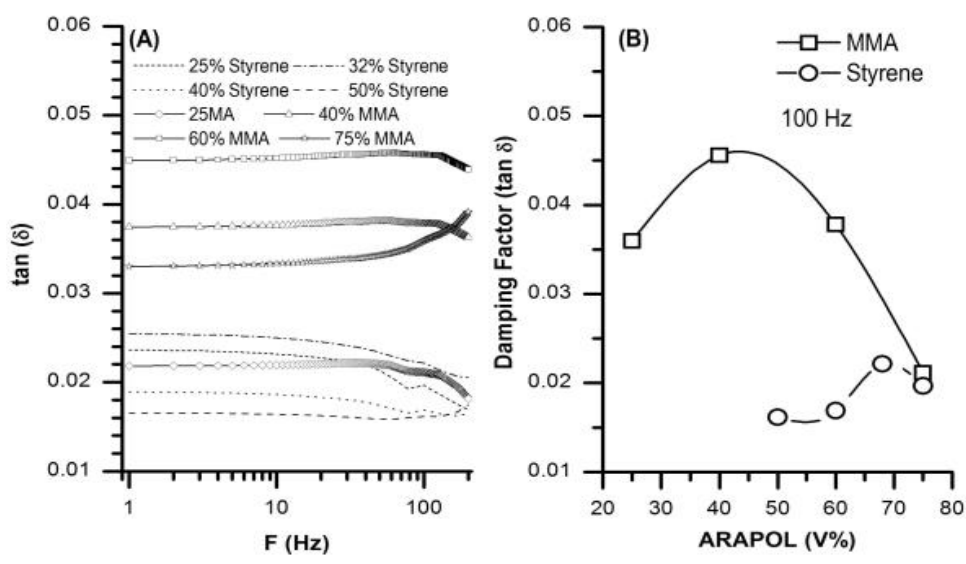

Figure 6: Damping factor of MMA and styrene - AROPOL resines in the range of (A) 0-200 Hz and (B) at $100 \mathrm{~Hz}$.

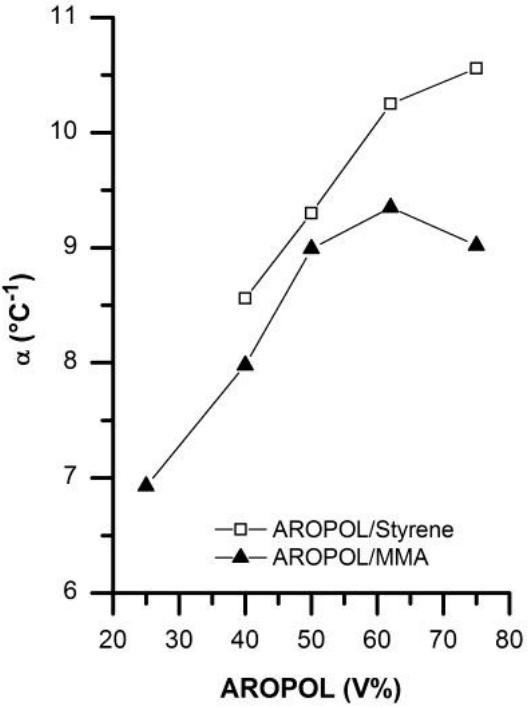

Figure 7: Coefficient of thermal expansion of MMA and styrene - AROPOL resines.

In PC, the CTE of the mortar resin is usually 7 to 10 times higher than the CTE of the aggregate [12]. Lowering the resin CTE to come closer to that of the aggregate and other components in PC bases of precision tool machines, produces a more homogeneous composite with uniform thermal expansion and less thermal stress. Figure 7 shows that the MMA-containing UPE resins have lower CTEs compared to the styrene- containing resins, in the $25-60^{\circ} \mathrm{C}$ temperature range. This is consistent with reports of low CTE for PC with poly methyl methacrylate as binding resin [39]. The CTE increases with increasing ARAPOL ratio.

The higher thermal expansion of the styrene-rich resin may be due to molecular packing factor of these resins, leaving only a small space for molecular expansion at increasing temperatures. The inclusion of MMA in the resin composition increases the spatial disorganization and lowers the molecular packing factor, allowing for the polymer chain expansion to be accommodated in the free space existing in the cross-linked network of the resin. This phenomenon can be studied by following the resin shrinkage during the curing process which was successfully reduced by adding montmorillonite filler in composite material [47].

\section{Conclusion}

The composition with the highest damping factor of all the resins is achieved with $40 \%$ ARAPOL/MMA, which has a damping factor of $5.46 \%$. The highest flexural strength is reached by the same composition with $128 \mathrm{MPa}$ and a low strain of $10.4 \%$. The highest tensile strength is reached by this composition. The lowest CTE is achieved by $25 \%$ ARAPOL/MMA $\left(6.93 \times 10^{-5} 1 /{ }^{\circ} \mathrm{C}\right)$, followed by $40 \%$ ARAPOL/MMA $\left(7.98 \times 10^{-5} 1 /{ }^{\circ} \mathrm{C}\right)$. The module of elasticity of the $40 \%$ ARAPOL/ MMA is $759 \mathrm{MPa}$. The highest Shore D hardness for 25\% ARAPOL/ MMA is 86.6 and 85.5 for $40 \%$ ARAPOL/MMA. The result of the mechanical properties shapes the focus for the rheological analysis of the ARAPOL/MMA compositions whilst not ignoring the ARAPOL/ styrene compositions. The effects of the UP/styrene in the ARAPOL/ styrene and UP/MMA/styrene ratios in ARAPOL/MMA composition were studied. It is concluded that the ARAPOL/MMA compositions are more suitable for consideration, since the mixing efficiency with the initiator and the promoter produce a more uniform solid resin. In addition, it may enhance the mixing of the aggregate with the liquid resin as well as by giving more time while the polymerizing mixture is still a flowing liquid. The exothermic temperature profile is relatively lower in the ARAPOL/MMA compositions than the ARAPOL/ styrene composition. The lowest composition in terms of exothermic temperature and viscosity is the 25\% ARAPOL/MMA, followed by the $40 \%$ ARAPOL/MMA. The mechanical properties of $25 \%$ ARAPOL/ MMA are very low compared to the $40 \%$ ARAPOL/MMA. This results in the nomination of the 40\% ARAPOL/MMA as the optimum binder for PC to be used in the manufacture of bases for precision tool machines, because it complies with most categories of the optimisation criteria at a good level.

\section{References}

1. Kamal MM, Tawfikand SY, Nosseir MH (1987) Polyester mortar. Journal of Applied Polymer Science 33: 1609-1622.

2. Şenand S, Nugay N (2000) Uncured and cured state properties of fly ash filled unsaturated polyester composites. Journal of Applied Polymer Science 77 1128-1136.

3. Atta A, Elnagdy S, Abdel-Raouf M, Elsaeedand S, Abdel-Azim AA (2005) Compressive properties and curing behaviour of unsaturated polyester resins in the presence of vinyl ester resins derived from recycled poly (ethylene terephthalate). Journal of Polymer Research 12: 373-383. 
Citation: Haddad H, Sbarski I (2017) Optimization of Thermal and Mechanical Properties of Unsaturated Polyester Resin as a Binder in Polymer Concrete for Manufacturing Precision Tool Machine Bases. J Material Sci Eng 6: 395. doi: 10.4172/2169-0022.1000395

Page 7 of 7

4. Gao JG, Liand SR, Kong DJ (2011) Reaction kinetics and physical properties of unsaturated polyester modified with methylacyloxylpropyl-POSS. Journal of Polymer Research 18: 621-626.

5. Hanand CD, Lee DS (1987) Analysis of the curing behavior of unsaturated polyester resins using the approach of free radical polymerization. Journal of Applied Polymer Science 33: 2859-2876.

6. Yangand H, Lee LJ (2001) Comparison of unsaturated polyester and vinylester resins in low temperature polymerization. Journal of Applied Polymer Science 79: $1230-1242$

7. Hanemann T, Schumacherand B, Haußelt J (2010) Polymerization conditions influence on the thermomechanical and dielectric properties of unsaturated polyester-styrene-copolymers. Microelectronic Engineering 87: 15-19.

8. Rodriguez EL (1991) The effect of free radical initiators and fillers on the cure of unsaturated polyester resins. Polym Eng Sci 31: 1022-1028.

9. Goodman SNE (1986) Handbook of Thermoset Plastics. Noyes Publications.

10. Huangand YJ, Chen CJ (1992) Curing of unsaturated polyester resins-effects of comonomer composition. I. Low-temperature reactions. Journal of Applied Polymer Science 46: 1573-1601.

11. Hanand CD, Lem KW (1983) Rheology of unsaturated polyester resins. II. Thickening behavior of unsaturated polyester and vinyl ester resins. Journal of Applied Polymer Science 28: 763-778.

12. Haddad H, Kobaisi MA (2012) Optimization of the polymer concrete used for manufacturing bases for precision tool machines. Composites Part B: Engineering 43: 3061-3068.

13. Ignacio C, Ferrazand V, Oréfice RL (2008) Study of the behavior of polyester concretes containing ionomers as curing agents. Journal of Applied Polymer Science 108: 2682-2690.

14. Do Suh J, Kim HS, Kim JM (2004) Design and manufacture of composite high speed machine tool structures. Composites Science and Technology 64: 15231530.

15. Cherianand AB, Thachil ET (2003) Blends of unsaturated polyester resin with functional elastomers. Journal of Elastomers and Plastics 35: 367-380.

16. Pachpinyo $P$, Lertprasertpong $P$, Chuayjuljit S, Sirisookand R, Pimpan V (2006) Preliminary study on preparation of unsaturated polyester resin/natural rubber latex blends in the presence of dispersion aids. Journal of Applied Polymer Science 101: 4238-4241.

17. Man S, Hashimand A, Akil H (2008) Studies on the curing behaviour and mechanical properties of styrene/methyl methacrylate grafted deproteinized natural rubber latex. Journal of Polymer Research 15: 357-364.

18. Radhakrishnan CK, Kumari P, Sujithand A, Unnikrishnan G (2008) Dynamic mechanical properties of styrene butadiene rubber and poly (ethylene-co-vinyl acetate) blends. Journal of Polymer Research 15: 161-171.

19. Ray D (2008) Journal of Reinforced Plastics and Composites.

20. Mansour SH, Tawfikand SY, Youssef MH (2002) Unsaturated polyester as compatibilizer for styrene-butadiene (SBR)/acrylonitrile-butadiene (NBR) rubber blends. Journal of Applied Polymer Science 83: 2314-2321.

21. De K, Caba L (1999) Fracture behavior-morphology relationships in an unsaturated polyester resin modified with a liquid oligomer. Journal of Polymer Science, Part B: Polymer Physics 37: 1677-1685.

22. Gao J, Dongand C, Du Y (2009) Nonisothermal curing kinetics and physica properties of unsaturated polyester modified with EA-POSS. International Journal of Polymeric Materials 59: 1-14.

23. Maspochand MLL, Martinez AB (1998) Toughening of unsaturated polyester with rubber particles. Part I: Morphological study. Polymer Engineering \& Science 38: 282-289.

24. Cherian B, Abrahamand BT, Thachil ET (2006) Modification of unsaturated polyester resin by polyurethane prepolymers. Journal of Applied Polymer Science 100: 449-456.
25. Singh B, Gupta M, Randhawa A, Tyagiand S, Sharma S (2011) Hybrid polymer networks of unsaturated polyester-urethane as composite matrices for jute reinforcement. Journal of Applied Polymer Science 122: 1206-1218.

26. Bucknall B (1992) Polymer International 29: 70-70.

27. Rodriguez $L$ (1993) The effect of reactive monomers and functional polymers on the mechanical properties of an unsaturated polyester resin. Polymer Engineering and Science 33: 115-121.

28. Vilas JL, Laza JM, Garay MT, Rodríguezand M, León LM (2001) Unsaturated polyester resins cure: Kinetic, rheologic, and mechanical-dynamical analysis. I. Cure kinetics by DSC and TSR. Journal of Applied Polymer Science 79: 447-457.

29. Liu CH, Yuand TL, Chen CC (2002) Effect of curing temperature on the morphology of unsaturated polyester resin blended with poly (vinyl acetate). Polymer Engineering \& Science 42: 567-581.

30. Li P, Yang X, Yuand Y, Yu D (2004) Cure kinetics, microheterogeneity, and mechanical properties of the high-temperature cure of vinyl ester resins. Journal of Applied Polymer Science 92: 1124-1133.

31. Kim HS, Parkand KY, Lee DG (1995) A study on the epoxy resin concrete for the ultra-precision machine tool bed. Journal of Materials Processing Technology 48: 649-655.

32. Sanchez EMS, Zavagliaand CAC, Felisberti MI (2000) Unsaturated polyester resins: influence of the styrene concentration on the miscibility and mechanical properties. Polymer 41: 765-769.

33. Zheng T, Ota T, Sato H, Tanaka K, Zhou SR (1988) Journal of Macromolecular Science: Part A - Chemistry 25:1-26.

34. Haqueand E, Armeniades CD (1985) pp: 1239-1242.

35. Zhang Y, Cai Q, Jiangand Z, Gong K (2004) Preparation and properties of unsaturated polyester-montmorillonite intercalated hybrid. Journal of Applied Polymer Science 92: 2038-2044.

36. Khristovaand Y, Aniskevich K (1995) Prediction of creep of polymer concrete. Mechanics of Composite Materials 31: 216-219.

37. RC Valore JR, Nausand DJ (1975) International Congress on Polymer Concretes London.

38. Munand K, Choi N (2008) Properties of poly methyl methacrylate mortars with unsaturated polyester resin as a crosslinking agent. Construction and Building Materials 22: 2147-2152.

39. Blaga JJBA (1985) Canadian Building Digests 242

40. Shah M, Zondervanand E, De Haan AB (2011) Process modeling for the synthesis of unsaturated polyester. Polymer Engineering and Science 51 2495-2504.

41. Gan LM, Lee KC, Chew CH, Ng SC, Ganand LH (1994) Macromolecules 27 6340 .

42. Linand CT, Liu MC (1995) Studies on the graft polymerizations of styrene and methyl methacrylate to hydroxyl terminated polybutadiene. Journal of Polymer Research 2: 127-132s.

43. Orakand S, Karademir S (1998) Poliester recineli polimer betonun sonum yetenegi uzerine bir arastirma 22: 323-327.

44. Bruni C, Forcellese A, Gabrielliand F, Simoncini M (2008) Hard turning of an alloy steel on a machine tool with a polymer concrete bed. Journal of Materials Processing Technology 202: 493-499.

45. Gale CL (1008) In Modern Machine Shop; Gardner Publications Inc.

46. Wongand CP, Bollampally RS (1999) Thermal conductivity, elastic modulus, and coefficient of thermal expansion of polymer composites filled with ceramic particles for electronic packaging. Journal of Applied Polymer Science 74 3396-3403.

47. Al-Khanbashi M, El-Gamaland A, Moet A (2005) Reduced shrinkage polyestermontmorillonite nanocomposite. Journal of Applied Polymer Science 98: 767-773. 